\title{
Gambaran Organizational Commitment (Studi Pada Karyawan di Perusahaan BUMN PT XYZ Regional Jabar)
}

\author{
Ifada Auli Azka \\ Magister Psikologi Profesi, Fakultas Psikologi, Universitas Padjajaran \\ ifadaauliazka@gmail.com \\ Diana Harding \\ Magister Psikologi Profesi, Fakultas Psikologi, Universitas Padjajaran \\ dhard_harding@yahoo.com \\ Yus Nugraha \\ Magister Psikologi Profesi, Fakultas Psikologi, Universitas Padjajaran \\ yoesdinain@yahoo.co.id
}

\begin{abstract}
The development of technology demands quality human resources. In a company, human resources have an important role that needs to be developed. Organizations need employees who remain to provide the best performance to support the achievement of the goals of the organization. The purpose of this study was to determine the general picture of organizational commitment in PT. West Java Regional XYZ. This type of research is quantitative descriptive, with a total of 128 research subjects. Based on the research results obtained by the commitment of employees of PT. West Java Regional XYZ based on normative commitment is 44\%, then continuance commitment is $35 \%$ and affective commitment is $21 \%$. These results indicate that the largest component of organizational commitment is normative commitment and the lowest is affective commitment. Suggestions for further researchers to be associated with several factors, such as psychological climate, organizational justice or other factors because it affects how organizational commitment to employees can be formed.
\end{abstract}

Keywords: organizational commitment; affective commitment; normative commitment; continuance commitment

\begin{abstract}
Abstrak
Perkembangan teknologi menuntut sumber daya manusia yang berkualitas. Dalam suatu perusahaan, sumber daya manusia memiliki peranan penting yang perlu dikembangkan. Organisasi membutuhkan karyawan yang tetap bertahan untuk memberikan kinerja terbaik agar mendukung pencapaian tujuan organisasi tersebut. Tujuan penelitian ini adalah untuk mengetahui gambaran secara umum organizational commitment pada karyawan PT. XYZ Regional Jabar. Jenis penelitian ini kuantitatif deskriptif, dengan jumlah subyek penelitian sebanyak 128 orang. Berdasarkan hasil penelitian diperoleh komitmen karyawan PT. XYZ
\end{abstract}


Regional Jabar yang didasari oleh normative commitment adalah sebesar 44\%, lalu continuance commitment sebesar $35 \%$ dan affective commitment sebasar $21 \%$. Hasil ini menunjukkan bahwa komponen terbesar dari organizational commitment adalah normative commitment dan yang terendah adalah affective commitment. Saran untuk peneliti selanjutnya agar dikaitkan dengan beberapa faktor, seperti psychological climate, organizational justice atau faktor lainnya karena hal tersebut mempengaruhi bagaimana komitmen organisasi pada karyawan dapat terbentuk.

Kata kunci: organizational commitment, affective commitment, normative commitment, continuance commitment

\section{Pendahuluan}

Perkembangan teknologi secara global menuntut sumber daya manusia yang berkualitas. Teknologi baru dan canggih akan dapat menyelesaikan masalah yang efektif dan efisien dengan pengoperasian dari sumber daya manusia yang telah berkembang pula. Dalam suatu organisasi atau perusahaan, sumber daya manusia memiliki peranan yang sangat penting dan dikatakan sebagai aset hidup yang perlu dikembangkan demi keberhasilan suatu organisasi dalam mencapai tujuan. Jika perusahaan ingin dapat bertahan dalam kondisi persaingan atau krisis yang dapat terjadi maka pengelolaan sumber daya manusia dalam perubahan organisasi yang lebih baik harus segera dilakukan.

Tahun ini menjadi tahun ketiga bagi PT. XYZ dinobatkan sebagai "Best Company To Work For In Asia 2019”. Penghargaan bergengsi tingkat Asia Pasifik yang diselenggarakan oleh Business Media Internasional. Penghargaan ini diberikan kepada perusahaan yang dinilai memberikan kenyamanan bekerja bagi karyawannya melalui program-program pengembangan diri dan lingkungan kerja yang kondusif bagi karyawan dalam meniti karir profesional.

Berdasarkan pengamatan dan wawancara awal yang dilakukan, dapat dikatakan bahwa PT. XYZ memiliki manajemen yang suportif. Manajemen memberikan dukungan terhadap pengembangan karyawannya serta memiliki perhatian yang besar terhadap kesejahteraan karyawan. PT. XYZ secara rutin memberikan apresiasi dan penghargaan terhadap kontribusi yang diberikan oleh karyawan. Pada kondisi lain karyawan merasakan adanya lingkungan kerja yang 
dirasakan positif terkait dengan rekan satu tim atau rekan kerja lainnya. Mereka setuju merasakan suasana yang layaknya sebuah keluarga. Tidak hanya itu, lingkungan kerja fisik juga membuat mereka sangat nyaman dengan perusahaan. Fasilitas yang diberikan oleh perusahaan juga memudahkan mereka dalam bekerja. Karyawan menyatakan bahwa dengan adanya kemudahan dalam bekerja, perasaan nyaman ketika menyelesaikan pekerjaan selalu dirasakan dan membuat mereka merasa betah untuk tetap bekerja disana.

Parker (2003) menjelaskan bahwa iklim psikologis merupakan suatu persepsi yang dibentuk oleh individu untuk mengintrepretasikan situasi dan mengukur kelayakan dari perilaku yang mereka tampilkan. Iklim psikologis merupakan penilaian subyektif individual terhadap lingkungannya yang dinilai berdasarkan persepsi secara psikologis yang dimaknai secara berbeda-beda sesuai dengan karakteristik individunya. Iklim psikologis ini akan dipersepsikan menyenangkan (favorable) oleh karyawan apabila karyawan merasa yakin bahwa kontribusi yang diberikan kepada organisasi bermanfaat, atau lingkungan yang ada disekitarnya menyenangkan bagi karyawan dalam bekerja. Begitu pula sebaliknya, karyawan akan memersepsikan unfavorable ketika ia merasa tidak yakin terhadap kontribusi yang diberikannya kepada organisasi bermanfaat, atau saat kondisi lingkungannya dipandang tidak menyenangkan untuknya bekerja. Perbedaan karakteristik karyawan akan berdampak pada penghayatannya mengenai kontribusi terhadap organisasi.

Berdasarkan pengambilan data awal berupa hasil observasi dan wawancara yang dilakukan oleh peneliti pada karyawan PT. XYZ Regional Jabar ditemukan beberapa fenomena yang terkait dengan pembahasan sikap kerja karyawan. Karyawan di PT. XYZ Regional Jabar nampak merespon dengan cepat pekerjaan yang diberikan oleh atasan dan langsung mengerjakan pekerjaaan tersebut. Meskipun terdapat pula karyawan yang tidak langsung mengerjakan pekerjaan yang diberikan oleh atasan dikarenakan sedang mengerjakan pekerjaan lain yang belum selesai.

Di sisi lain, terdapat pula keluhan dari atasan perihal proses dan hasil kerja karyawan yang tidak sesuai dengan yang diharapkan. Hal lainnya karyawan sudah 
melakukan cek kehadiran namun tetap terlambat untuk datang keruangan, atau sebaliknya karyawan melakukan cek kehadiran jam pulang tepat waktu, padahal karyawan pulang terlebih dahulu. Hal tersebut dapat dilakukan karena pengecekan kehadiran dilakukan melalui handphone. Karyawan mengatakan bahwa alasan mereka terlambat masuk ke dalam ruangan karena mereka sarapan terlebih dahulu atau mengobrol dengan karyawan lain di luar ruangan. Karyawan yang pulang terlebih dahulu karena memiliki keperluan lain seperti menjemput anak atau istri. Meskipun begitu, mereka mengatakan pekerjaan akan tetap dikerjakan dan selesai sesuai dengan tenggat waktu yang telah ditetapkan, karena itu sudah menjadi tanggung jawab mereka.

Selain itu, sebagian karyawan menyatakan bahwa mereka tidak keberatan untuk bekerja melebihi waktu dan melebihi dari area tanggung jawabnya selama mereka merasa masih mampu untuk mengerjakan. Hal tersebut dikarenakan mereka merasa jika bukan mereka yang mengerjakan, siapa lagi yang akan mengerjakan pekerjaan tersebut. Menurut mereka, itu merupakan salah satu bentuk terima kasih atas apa yang sudah diberikan oleh perusahaan pada mereka. Banyak pula karyawan yang bersedia bekerja lembur untuk menyelesaikan pekerjaan yang menjadi tanggung jawabnya, padahal perusahan tidak memberikan tunjangan bagi yang bekerja lembur.

Berdasarkan fenomena yang terjadi tersebut, peneliti menyimpulkan bahwa fenomena-fenomena yang didapatkan selama melakukan wawancara dan observasi merujuk pada fenomena yang terkait dengan sikap kerja khususnya organizational commitment. Parker (2006) mengemukakan bahwa terdapat korelasi positif terhadap munculnya organizational commitment di sebuah perusahaan dari hasil penghayatannya terhadap iklim psikologis.

Wawancara awal dilakukan terhadap karyawan PT. XYZ Regional Jabar didapatkan bahwa terdapat beberapa alasan yang berbeda mengapa mereka bertahan bekerja di PT. XYZ Regional Jabar. Beberapa diantaranya adalah karena adanya kesempatan untuk mengembangkan diri, gaji yang cukup memenuhi kebutuhan dan sesuai dengan harapan, lingkungan kerja yang nyaman, kejelasan sistem peran dan tugas, apresiasi dan dukungan dari perusahaan. Dari data 
tersebut dapat dilihat bahwa masing-masing karyawan memiliki dasar keterikatan yang berbeda-beda yang menjadikan alasan mereka tetap memilih untuk bekerja di PT. XYZ Regional Jabar. Perbedaan dasar keterikatan untuk bertahan di PT. XYZ Regional Jabar membuat sikap kerja yang ditampilkan oleh karyawan berbeda pula, seperti yang sudah dijabarkan sebelumnya.

Dalam rangka untuk mencapai tujuan yang diharapkan oleh sebuah organisasi, organisasi membutuhkan karyawan yang tetap bertahan untuk memberikan kinerja terbaik dalam rangka mendukung pencapaian tujuan organisasi tersebut. Komitmen secara umum dapat diartikan sebagai suatu keadaan dimana seorang karyawan memihak pada suatu organisasi tertentu dan tujuan-tujuannya serta berniat memelihara keanggotaan dalam organisasi itu (Robbins, 2001:92). Organizational commitment adalah keadaan psikologis yang memiliki karakteristik mengenai hubungan karyawan dengan organisasi, dan memiliki implikasi terhadap keputusan untuk meneruskan keanggotaan di organisasi (Meyer \& Allen, 1997).

Meyer \& Allen (1997) mengemukakan bahwa terdapat tiga komponen dari komitmen organisasi yaitu: affective, continuance, dan normative. Dominasi dari setiap komponen yang dihayati oleh karyawan akan berpengaruh pada kinerja yang ditampilkan guna mendukung pencapaian tujuan PT. XYZ Regional Jabar. Berdasarkan uraian tersebut maka peneliti tertarik untuk melihat secara menyeluruh bagaimana gambaran Organizational commitment pada karyawan PT. XYZ Regional Jabar.

\section{Metode}

Penelitian ini menggunakan pendekatan kuantitatif yang bertujuan untuk mendapatkan gambaran terkait dengan varaibel penelitian yaitu Organizational commitment. Metode pengumpulan data pada penelitian ini menggunakan skala dari Meyer dan Allen (1997) yang akan diadaptasi dan dimodifikasi oleh peneliti. Alat ukur ini akan menampilkan profil yang menggambarkan tiga komponen organizational commitment yang mendasari karyawan untuk mempertahankan keanggotaannya dalam perusahaan yaitu affective commitment, normative 
commitment dan continuance commitment. Hasil uji validitas pada alat ukur organizational commitment dengan menggunakan metode cronbach's alpha menunjukkan nilai reliabilitas 0.812. berdasarkan skala Guilford, data yang didapat menunjukkan nilai reliabilitas yang tinggi. Metode analisa data yang digunakan dalam penelitian ini adalah kuantitatif deskriptif, agar peneliti mengetahui gambaran secara detil mengenai organizational commitment.

Dalam penelitian ini, untuk mendapatkan jumlah sampel yang proporsional dan dianggap mewakili karyawan PT. XYZ Regional Jabar, penentuan jumlah sampel akan menggunakan pengukuran jumlah sampel yang dikembangkan oleh Krejcie dan Morgan (1970). Krejcie dan Morgan (1970) telah mengembangkan suatu rumus dijadikan sebuah tabel yang siap pakai. Tabel tersebut menggunakan tingkat kepercayaan 95\%. Berdasarkan tabel Krejcie dan Morgan tersebut, batas minimal sampel dengan jumlah populasi 190 orang adalah sebanyak 127 orang. Akan tetapi, karena populasi berjumlah 192 orang, maka peneliti mengambil sampel sebanyak 128 orang. Teknik pengambilan sampel menggunakan simple random sampling.

\section{Hasil Penelitian}

Berdasarkan hasil analisa data yang dikumpulkan, dapat dilihat bahwa komitmen karyawan PT. XYZ Regional Jabar yang didasari oleh normative commitment adalah sebesar $44 \%$, lalu continuance commitment sebesar $35 \%$ dan affective commitment sebasar $21 \%$.

Diagram 1 Gambaran Organizational Commitment

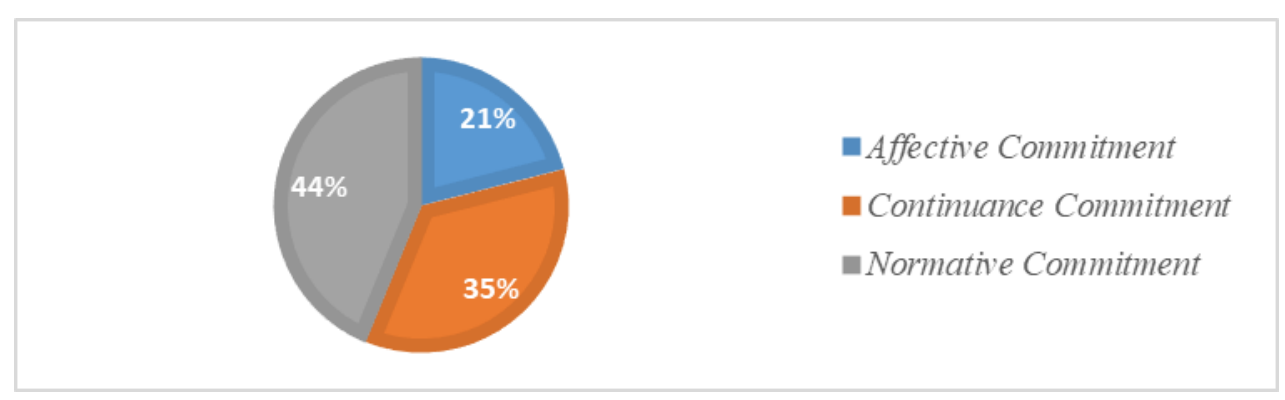


Berdasarkan data yang terkumpul, dapat diketahui karakteristik subyek yang terlibat dalam penelitian ini. Beberapa deskripsi penelitian, dapat dilihat sebagai berikut :

Tabel 1 Perbedaan Affective Commitment Berdasarkan Jenis Kelamin

\begin{tabular}{lccccc}
\hline Jenis Kelamin & Mean & N & Std. Deviation & $\begin{array}{c}\text { Std. Error of } \\
\text { Mean }\end{array}$ & Sig. \\
\hline Laki-laki & 21,86 & 77 & 1,812 &, 206 & 0,000 \\
\hline Perempuan & 20,43 & 51 & 2,042 &, 286 & \\
\hline Total & $\mathbf{2 1 , 2 9}$ & $\mathbf{1 2 8}$ & $\mathbf{2 , 0 2 4}$ & $\mathbf{1 7 9}$ & \\
\hline
\end{tabular}

Dari tabel di atas dapat dilihat bahwa affective commitment berdasarkan jenis kelamin memiliki nilai signifikansi $0,000(\alpha<0,05)$, artinya ada perbedaan yang signifikan antara affective commitment pada karyawan laki-laki dengan affective commitment pada karyawan perempuan PT. XYZ Regional Jabar.

Tabel 2 Perbedaan Affective Commitment Berdasarkan Masa Kerja

\begin{tabular}{cccccc}
\hline Masa Kerja & Mean & N & Std. Deviation & Std. Error of Mean & Sig. \\
\hline$\leq 5$ & 20,39 & 23 & 1,699 &, 354 & 0,002 \\
\hline $6-10$ & 21,80 & 5 & 1,643 &, 735 & \\
\hline $11-15$ & 21,50 & 8 & 1,773 &, 627 & \\
\hline $16-20$ & 22,80 & 5 & 1,789 &, 800 \\
\hline $21-25$ & 20,31 & 16 & 1,922 &, 323 \\
\hline $26-30$ & 22,38 & 24 & 1,583 &, 320 \\
\hline $31-35$ & 21,33 & 46 & 2,171 &. & \\
\hline$>35$ & 18,00 & 1 &. & $\mathbf{1 7 9}$ & \\
\hline Total & $\mathbf{2 1 , 2 9}$ & $\mathbf{1 2 8}$ & $\mathbf{2 , 0 2 4}$ & & \\
\hline
\end{tabular}

Dari tabel di atas dapat dilihat bahwa affective commitment berdasarkan masa kerja memiliki nilai signifikansi $0.002(\alpha<0.05)$, artinya ada perbedaan affective commitment yang signifikan diantara karyawan PT. XYZ Regional Jabar berdasarkan masa kerjanya.

Tabel 3 Perbedaan Continuance Commitment Berdasarkan Jenis Kelamin

\begin{tabular}{lccccc}
\hline Jenis Kelamin & Mean & N & Std. Deviation & $\begin{array}{c}\text { Std. Error of } \\
\text { Mean }\end{array}$ & Sig. \\
\hline Laki Laki & 21,48 & 77 & 2,717 &, 310 & 0,446 \\
\hline Perempuan & 21,10 & 51 & 2,851 &, 399 & \\
\hline Total & $\mathbf{2 1 , 3 3}$ & $\mathbf{1 2 8}$ & $\mathbf{2 , 7 6 7}$ & $\mathbf{2 4 5}$ & \\
\hline
\end{tabular}

Dari tabel di atas dapat dilihat bahwa continuance commitment berdasarkan jenis kelamin memiliki nilai signifikansi 0,446 $(\alpha>0,05)$, artinya 
tidak ada perbedaan yang signifikan antara continuance commitment pada karyawan laki-laki dengan continuance commitment pada karyawan perempuan PT. XYZ Regional Jabar.

Tabel 4 Perbedaan Continuance Commitment Berdasarkan Masa Kerja

\begin{tabular}{cccccc}
\hline Masa Kerja & Mean & N & Std. Deviation & Std. Error of Mean & Sig. \\
\hline$\leq 5$ & 19,35 & 23 & 3,366 &, 702 & 0,013 \\
\hline $6-10$ & 21,80 & 5 & 2,588 & 1,158 & \\
\hline $11-15$ & 22,00 & 8 & 3,162 & 1,118 \\
\hline $16-20$ & 21,00 & 5 & 2,550 & 1,140 \\
\hline $21-25$ & 21,88 & 16 & 2,655 &, 664 \\
\hline $26-30$ & 22,42 & 24 & 2,717 &, 555 \\
\hline $31-35$ & 21,46 & 46 & 2,073 &, 306 & \\
\hline$>35$ & 20,00 & 1 &. & $\mathbf{2 4 5}$ \\
\hline Total & $\mathbf{2 1 , 3 3}$ & $\mathbf{1 2 8}$ & $\mathbf{2 , 7 6 7}$ &
\end{tabular}

Dari tabel di atas dapat dilihat bahwa continuance commitment berdasarkan masa kerja memiliki nilai signifikansi $0.013(\alpha<0.05)$, artinya ada perbedaan continuance commitment yang signifikan diantara karyawan PT. XYZ Regional Jabar berdasarkan masa kerjanya.

Tabel 5 Perbedaan Normative Commitment Berdasarkan Jenis Kelamin

\begin{tabular}{lccccc}
\hline Jenis Kelamin & Mean & N & Std. Deviation & $\begin{array}{c}\text { Std. Error of } \\
\text { Mean }\end{array}$ & Sig. \\
\hline Laki-laki & 24,47 & 77 & 2,850 &, 325 & 0,000 \\
\hline Perempuan & 21,80 & 51 & 4,118 &, 577 & \\
\hline Total & $\mathbf{2 3 , 4 1}$ & $\mathbf{1 2 8}$ & $\mathbf{3 , 6 4 0}$ & $\mathbf{3 2 2}$ & \\
\hline
\end{tabular}

Dari tabel di atas dapat dilihat bahwa normative commitment berdasarkan jenis kelamin memiliki nilai signifikansi $0,000(\alpha<0,05)$, artinya ada perbedaan yang signifikan antara normative commitment pada karyawan laki-laki dengan normative commitment pada karyawan perempuan PT. XYZ Regional Jabar.

Tabel 6 Perbedaan Normative Commitment Berdasarkan Masa Kerja

\begin{tabular}{cccccc}
\hline Masa Kerja & Mean & N & Std. Deviation & Std. Error of Mean & Sig. \\
\hline$\leq 5$ & 20,83 & 23 & 3,380 &, 705 & 0,000 \\
\hline $6-10$ & 23,40 & 5 & 3,782 & 1,691 & \\
\hline $11-15$ & 20,88 & 8 & 5,357 & 1,894 & \\
\hline $16-20$ & 26,00 & 5 & 2,739 & 1,225 & \\
\hline $21-25$ & 23,75 & 16 & 3,958 &, 590 & \\
\hline $26-30$ & 25,25 & 24 & 2,541 &, 453 & \\
\hline $31-35$ & 23,83 & 46 & 3,072 &. & \\
\hline$>35$ & 21,00 & 1 & $\mathbf{3 2 2}$ &
\end{tabular}


Dari tabel di atas dapat dilihat bahwa normative commitment berdasarkan masa kerja memiliki nilai signifikansi $0.000(\alpha<0.05)$, artinya ada perbedaan normative commitment yang signifikan diantara karyawan PT. XYZ Regional Jabar berdasarkan masa kerjanya.

\section{Pembahasan}

Berdasarkan hasil analisa data yang dikumpulkan, dapat dilihat bahwa komitmen karyawan PT. XYZ Regional Jabar yang didasari oleh normative commitment adalah sebesar $44 \%$, lalu continuance commitment sebesar $35 \%$ dan affective commitment sebasar $21 \%$. Dengan kata lain, sebagian besar karyawan di PT. XYZ Regional Jabar menjadikan normative commitment sebagai dasar keterikatannya untuk tetap bertahan bekerja di PT. XYZ Regional Jabar. Hal ini dapat diartikan bahwa keputusan karyawan PT. XYZ Regional Jabar untuk tetap bertahan di perusahaan paling banyak didasari oleh perasaan wajib karena sebuah keharusan (ought to) untuk bisa setia pada perusahaan dan pekerjaannya sebagai karyawan PT. XYZ Regional Jabar.

Normative commitment dapat terbentuk dari psychological contract antara karyawan dengan perusahaan (Argyris, 1960; Rousseau, 1989, 1995; Schein, 1980). Komitmen normatif karyawan dapat tinggi jika organisasi menanamkan kepercayaan pada karyawan bahwa organisasi mengharapkan loyalitas karyawan maka karyawan juga akan menunjukkan komitmen normatif yang tinggi. Hal ini dilakukan oleh PT. XYZ sejak pertama kali karyawan masuk ke dalam perusahaan melalui proses sosialisasi, bahwa perusahaan mengharapkan loyalitas mereka. Hal inilah yang disebut psychological contract. Normative commitment dapat terbentuk dari psychological contract antara karyawan dengan perusahaan (Argyris, 1960; Rousseau, 1989, 1995; Schein, 1980).

Psychological contract terdiri dari belief individu mengenai sejumlah pertukaran hubungan antara individu dan perusahaan yang sifatnya timbal balik (Meyer \& Allen, 1997: 61). Persentase tertinggi pada komponen ini menyatakan adanya tanggung jawab untuk menyelesaikan pekerjaan. Munculnya tanggung jawab adalah untuk memberi balasan atau harapan-harapan karyawan yang telah 
dipenuhi oleh PT. XYZ Regional Jabar. Karyawan PT. XYZ Regional Jabar merasakan bahwa perusahaan telah memenuhi kebutuhan dan harapan mereka, dengan kata lain psychological contract telah terpenuhi dan menghasilkan karyawan PT. XYZ Regional Jabar yang berkomitmen.

Komponen organizational commitment kedua terbanyak yang menjadi dasar keterikatan karyawan PT. XYZ Regional Jabar adalah continuance commitment. Hal ini dapat diartikan bahwa karyawan cenderung akan mengikatkan diri pada organisasinya karena ada suatu kebutuhan yang sifatnya personal (need to do). Continuance commitment dapat berkembang karena adanya berbagai tindakan atau kejadian yang dapat meningkatkan kerugian jika meninggalkan organisasi. Beberapa tindakan atau kejadian ini dapat dibagi ke dalam dua variabel, yaitu investasi dan alternatif. Investasi termasuk sesuatu yang berharga, termasuk waktu, usaha ataupun uang, yang harus individu lepaskan jika meninggalkan organisasi. Sedangkan alternatif adalah kemungkinan untuk masuk ke organisasi lain.

Karyawan PT. XYZ Regional Jabar menyadari bahwa perusahaannya saat ini merupakan perusahaan besar yang dapat memberikan jaminan bagi keberlangsungan hidup mereka. Dari segi pendapatan, perusahaan memberikan pendapatan yang lebih dari untuk memenuhi kebutuhan hidup sehari-hari. Terlebih perusahaan memberikan berbagai hal lain diluar pendapatan yang membuat karyawan ingin tetap bertahan bekerja di PT. XYZ Regional Jabar, seperti jaminan kesehatan, jaminan untuk pensiun, fasilitas yang memadai, dan lain sebagainya. Hal tersebut tentu saja belum tentu karyawan dapatkan di perusahaan lain. Karyawan PT. XYZ Regional Jabar merasa bahwa mereka akan merugi jika meninggalkan perusahaan dengan segala hal menguntungkan yang telah diberikan, karena hal tersebut dianggap suatu investasi oleh mereka.

Di sisi lain, terdapat pula karyawan yang bertahan untuk bekerja di PT. XYZ Regional Jabar karena kecilnya kemungkinan untuk masuk ke perusahaan lain. Mengingat sebagian besar karyawan adalah karyawan yang berusia antara 51-55 tahun yaitu sebesar 38\%, dan berusia lebih lebih dari 55 tahun sebesar $21 \%$, tentu saja mereka menyadari bahwa untuk pindah ke perusahaan lain di usia 
mereka saat ini sudah tidak lagi memungkinkan. Oleh sebab itu, pertimbangan untung rugi menjadi dasar yang cukup kuat bagi karyawan PT. XYZ Regional Jabar untuk tetap bertahan.

Komponen organizational commitment yang menjadi dasar keterikatan paling sedikit pada karyawan PT. XYZ Regional Jabar adalah affective commitment, yaitu sebesar $21 \%$. Terdapat beberapa penelitian mengenai antecedents dari affective commitment. Antecendents yang pertama adalah karakterisitik organisasi. Karakteristik organisasi yang mempengaruhi perkembangan affective commitment adalah sistem desentralisasi (Bateman \& Strasser, 1984; Morris \& Steers, 1980). Berbeda dengan hal tersebut, PT. XYZ memiliki sistem sentralisasi. PT. XYZ Regional Jabar merupakan salah satu unit organisasi berbentuk Divisi yang dibentuk dengan berbasis geografis dan cakupan kawasan operasionalnya adalah Jawa Barat. Seperti layaknya unit organisasi, semua kebijakan menginduk pada PT. XYZ Pusat. Meskipun demikian, ada beberapa kebijakan yang memang berbeda tergantung dari kawasan operasionalnya. Misalnya target yang harus dicapai dari penjualan produk. Target penjualan produk pada PT. XYZ Regional Jabar dengan Regional lain berbeda. Namun demikian, semua keputusan terkait hal tersebut berdasarkan kebijakan dari PT. XYZ pusat. Berdasarkan karakteristik organisasi tersebut, dapat dilihat bahwa dengan kenyataan PT. XYZ memiliki sistem sentralisasi, hal ini dapat menjadi salah satu faktor yang menyebabkan hanya sedikit karyawan yang memiliki affective commitment sebagai dasar keterikatan untuk tetap bertahan di PT. XYZ. Meskipun begitu, terdapat antecedents lain yang memengaruhi berkembangnya affective commitment, yaitu karakteristik individu, dan pengalaman kerja.

Karakteristik individu seperti jenis kelamin mempengaruhi affective commitment, namun ada pula yang menyatakan tidak demikian (Aven, Parker, \& McEvoy; Mathieu \&Zajac dalam Allen \& Meyer, 1997). Selain itu usia juga mempengaruhi proses terbentuknya affective commitment, meskipun tergantung dari beberapa kondisi individu sendiri (Allen \& Meyer, 1993), organizational tenure (Cohen; Mathieu \& Zajac dalam Allen \& Meyer, 1997), status pernikahan, tingkat pendidikan, kebutuhan untuk berprestasi, etos kerja, dan persepsi individu 
mengenai kompetensinya (Allen \& Meyer, 1997) (Dispositional variables). Selain itu terdapat antecedents yang terakhir, yaitu pengalaman kerja yang menunjukkan kepuasan dan motivasi individu (Hackman \& Oldham, 1980 dalam Allen \& Meyer, 1997). Hal ini mencakup tantangan dalam pekerjaan, tingkat otonomi individu, dan variasi kemampuan yang digunakan individu. Selain itu peran individu dalam organisasi tersebut (Mathieu \& Zajac, 1990 dalam Allen \& Meyer, 1997) dan hubungannya dengan atasan. Dengan adanya ketiga antecedents tersebut, dapat dikatakan bahwa banyak faktor yang memengaruhi karyawan PT. XYZ Regional Jabar untuk tidak didominasi dasar keterikatan affective commitment.

\section{Kesimpulan dan Saran}

\section{Kesimpulan}

1. Komitmen karyawan PT. XYZ Regional Jabar yang didasari oleh normative commitment adalah sebesar $44 \%$, lalu continuance commitment sebesar $35 \%$ dan affective commitment sebasar $21 \%$.

2. Affective commitment berdasarkan jenis kelamin memiliki nilai signifikansi $0,000(\alpha<0,05)$, artinya ada perbedaan yang signifikan antara affective commitment pada karyawan laki-laki dengan affective commitment pada karyawan perempuan PT. XYZ Regional Jabar.

3. Affective commitment berdasarkan masa kerja memiliki nilai signifikansi $0.002(\alpha<0.05)$, artinya ada perbedaan affective commitment yang signifikan diantara karyawan PT. XYZ Regional Jabar berdasarkan masa kerjanya.

4. Continuance commitment berdasarkan jenis kelamin memiliki nilai signifikansi $0,446(\alpha>0,05)$, artinya tidak ada perbedaan yang signifikan antara continuance commitment pada karyawan laki-laki dengan continuance commitment pada karyawan perempuan PT. XYZ Regional Jabar.

5. Continuance commitment berdasarkan masa kerja memiliki nilai signifikansi $0.013(\alpha<0.05)$, artinya ada perbedaan continuance 
commitment yang signifikan diantara karyawan PT. XYZ Regional Jabar berdasarkan masa kerjanya.

6. Normative commitment berdasarkan jenis kelamin memiliki nilai signifikansi $0,000(\alpha<0,05)$, artinya ada perbedaan yang signifikan antara normative commitment pada karyawan laki-laki dengan normative commitment pada karyawan perempuan PT. XYZ Regional Jabar.

7. Normative commitment berdasarkan masa kerja memiliki nilai signifikansi $0.000(\alpha<0.05)$, artinya ada perbedaan normative commitment yang signifikan diantara karyawan PT. XYZ Regional Jabar berdasarkan masa kerjanya.

\section{Saran}

Saran untuk peneliti selanjutnya agar mendapatkan gambaran yang lebih utuh terkait komitmen organisasi maka akan lebih baik bila dikaitkan dengan beberapa faktor, seperti psychological climate, psychological capital, work family conflict, organizational justice dan lain sebagainya sebagai hal-hal yang memperngaruhi bagaimana komitmen organisasi pada karyawan dapat terbentuk.

\section{DAFTAR PUSTAKA}

Angle, H. L., Perry, J. L. (1981). An Empirical Assessment of Organizationl Commitment and Organizational Effectiveness. Administrative Science Quarterly, Vol. 26, No 1, $1-14$

Balogun, A., Adetulla, G., Olowodunoye, S. (2013). Job Condition, Psychological Climate and Affective Commitment as Predictors of Intention to Quit among Two Groups of Bank Employees in Nigeria. Romanian Journal of Applied Psychology, Vol. 15, No. 1, 9-19.

Bateman, T.S., \& Strasser, S. (1984). A Longitudinal Analysis Of The Antecedents Of Organizational Commitment. Academy of Management Journal, 27, 95-112

Creswell, J. W. (2010). Research Design : Pendekatan Kualitatif, Kuantitatif, dan Mixed. Yogyakarta : Pustaka Belajar.

Cummings, T. G., Worley, C. G. (2005). Organizational Commitment and Change $8^{\text {th }}$ Edition. USA: Thomson Corporation 
Gulo, W. (2003). Metodologi Penelitian. Jakarta: Grasindo

Hassan, S., \& Rohrbaugh, J. (n.d.). The Role of Psychological Climate on Organizational Commitment: Reporting Reslut of Two Field Studies from State Goverment Agencies. Rokefeller College of Public Affairs and Policy, University at Albany.

Kahn, T. I., (2011). Job Involvement as Predictor of Employee Commitment, Evidence from Pakistan. Journal of Business Management, 1-11.

Krejcie, R, \& Morgan, D., (1970). Determining Sample Size for Research Activities. Educational and Psychologcal Measurement, 30(3), 607-610.

Meyer, J.P. \& Allen, N.J. (1997). Commitment in the Workplace. Theory, Research, and Application. Sage Publicatiobs, Inc.

Meyer, J.P. \& Allen, N.J. (1991). The Measurement and Antecedents of Affective, Continuence and Normative Commitment Organization. Journal of Occupational Psychology, 63, 1-18

Mowday, R. T., Steers, R. M., \& Porter, L.W. (1979). The Measurement of Organizational Commitment. Journal of Vocational Behaviour, 14, 224247. http://dx.doi.org/10.1016/0001-8791(79)90072-1

Robbins S., (1996) Organizational Behavior: Concepts, Controversies, and Applications., San Diego State Uniersity, Prentice Hall International Inc.

Sugiyono. (2009). Statistika untuk Penelitian. Bandung : AlfaBeta. 